Pesq. Vet. Bras. 36(12):1190-1193, dezembro 2016

DOI: $10.1590 /$ S0100-736X2016001200009

\title{
Bullous keratopathy in a yellow-headed caracara (Milvago chimachima) treated with a modified third eyelid flap ${ }^{1}$
}

\author{
Arianne P. Oriáz ${ }^{*}$, Deusdete C. Gomes Junior², Ana Cláudia S. Raposo ${ }^{2}$, Fernanda A. \\ Libório $^{3}$, Débora P.H. Schäffer ${ }^{2}$ and Francisco A. Dórea Neto ${ }^{2}$
}

\begin{abstract}
Oriá A.P., Gomes Junior D.C., Raposo A.C.S., Libório F.A., Schäffer D.P.H. \& Dórea Neto F.A. 2016. Bullous keratopathy in a yellow-headed caracara (Milvago chimachima) treated with a modified third eyelid flap. Pesquisa Veterinária Brasileira 36(12):1190-1193. Escola de Medicina Veterinária e Zootecnia, Universidade Federal da Bahia, Av. Adhemar de Barros 500, Ondina, Salvador, BA 40170-110, Brazil. E-mail: arianneoria@ufba.br

A Yellow-headed Caracara (Milvago chimachima) was submitted to the Ophthalmology Service of the Federal University of Bahia with a corneal abnormality. During ophthalmic evaluation the right cornea was stained positively with fluorescein; a blurred bullous lesion, with irregular surface, compatible with the diagnosis of bullous keratopathy was found. This is a rare condition in a bird which was treated successfully with a modified third eyelid flap associated with antibiotic and hyaluronic acid eye drops. The adopted therapeutic proved to be simple to implement and viable for repair of the bullous keratopathy in the Yellow-headed caracara.
\end{abstract}

INDEX TERMS: Bullous keratopathy, yellow-headed caracara, Milvago chimachima, third eyelid flap, cornea, birds, hyaluronic acid, endothelial dystrophy.

RESUMO.- [Ceratopatia bolhosa em caracará (Milvago chimachima) tratado com flap de terceira pálpebra modificado.] Um gavião carrapateiro (Milvago chimachi$m a$ ) foi encaminhado ao Serviço de Oftalmologia Veterinária da Universidade Federal da Bahia com alteração em córnea. Durante a avaliação oftálmica a prova da fluoresceína foi positiva no olho direito e foi observado lesão bolhosa de aspecto irregular, compatível com o diagnóstico de ceratopatia bolhosa. Esta é uma alteração rara em aves e no presente caso foi tratada através de "flap" modificado de terceira pálpebra associado a utilização de colírio antibiótico e ácido hialurônico. A terapêutica adotada foi de fácil implementação e viável no reparo da ceratopatia bolhosa em gavião carrapateiro.

TERMOS DE INDEXAÇÃO: Ceratopatia bolhosa, caracará, Milvago chimachima, flap de terceira pálpebra modificado, córnea, ave, ácido hialurônico, distrofia endotelial.

\footnotetext{
${ }^{1}$ Receive on August 4, 2015.

Accept for publication on July 29, 2016.

${ }^{2}$ Faculdade de Medicina Veterinária e Zootecnia, Universidade Federal da Bahia (UFBA), Av. Adhemar de Barros 500, Ondina, Salvador, BA 40170110, Brazil. *Corresponding author: arianneoria@ufba.br

${ }^{3}$ Centro de Triagem de Animais Silvestres (Cetas-IBAMA), Estrada das Barreiras, Salvador, BA 41195-220, Brazil.
}

\section{INTRODUCTION}

The yellow-headed caracara (Milvago chimachima) is a common bird of the Falconidae family with distribution in Central and South America which inhabits treeless plains, green and urban areas. They have a daytime habit with accurate vision like other birds of prey (Ossa \& Ossa-Lacayo 2011).

Traumatic ulcers, keratitis and edema are the most frequently corneal diseases reported in birds (Harris et al. 2008). Bullous keratopathy (BK) is a corneal disease caused by endothelial decompensation due to endothelial dystrophy, trauma or glaucoma (Pires et al. 1999, Maggs et al. 2013), which leads to stromal epitelial edema and a subepithelial bullae formation (Famose 2014). The etiology and pathogenesis of feline bullous keratopathy is unknown (Glover et al. 1994). In dogs, breed related endothelial dystrophy, trauma, uveitis, and age-related endothelial degeneration can impair the endothelial pump function and result in a BK.

Medical treatment like hypertonic saline and antibiotic solutions are indicated when small limited portion of the cornea is affected or if the bullae rupture and fluorescein is retained by the exposed stroma (Maggs et al. 2013). Surgical intervention is indicated when failure occurs in medical treatment of small lesions or when they occupy a large por- 
tion of the cornea. The available surgical options include keratectomy and keratoplasty, conjunctival flaps, tarsorraphy, collagen cross-linking and the amniotic membrane transplantation (Pires et al. 1999, Ortiz et al. 2011, Maggs et al. 2013, Zhao et al. 2013, Spiess et al. 2014, Pot et al. 2015, Famose 2014).

In cats it has been successfully used a long-term third eyelid flap in the treatment of BK which acts as a pressure bandage (Martin 2005). According to some authors this surgical technique is not recommended in birds due to thin structure of the third eyelid and its peculiar movement (Willis \& Wilkie 1999). To the best knowledge of the authors, no case of bullous keratopathy in Yellow-headed Caracara treated with a third eyelid flap has ever been reported.

\section{CASE REPORT}

All protocols were in accordance with the Authorization and Information System on Biodiversity of the Ministry of Environment of Brazil (process n. 27489-1). In addition, all procedures were conducted in accordance with the humane principles set forth in the ARVO Statement for the Use of Animals in Ophthalmic and Vision Research. A Yellow-headed Caracara (Milvago chimachima) of approximately one year of age weighing $0.35 \mathrm{~kg}$, from the Triage Center for Wild Animals (Ctas-IBAMA, Salvador, Bahia) was presented to the Ophthalmology Service of the Federal University of Bahia with a corneal abnormality.

After physical restraint the animal was evaluated. The eyes and periocular regions were examined in normal light for gross abnormalities with a binocular magnifying loupe $3 \mathrm{X}$ and a tran- silluminator. No changes were observed in face or eyelids and a blurred bullous lesion was identified, with irregular surface, occupying almost the entire cornea of the right eye (Fig.1A). Due to the appearance of the cornea it was not possible to assess the intraocular structures. Fluorescein dye was positive and a diagnoses of bullous keratopathy due to corneal ulceration was made. No changes were observed in the left eye. Due to the extent of the lesion and since it is a bird that could not be holded or manipulated many times a day for topical medication, it was decided to perform a surgical approach by conducting a modified third eyelid flap.

The animal was premedicated with butorphanol tartrate (Torbugesic ${ }^{\circledR}$, Fort Dodge Saúde Animal, São Paulo, Brazil) (0.3mg kg-1, i.m.) and general anesthesia was induced with isoflurane (Vetflurano ${ }^{\circledR}$, Virbac, São Paulo, Brazil) diluted in oxygen using a facial mask. Immediately after unconsciousness the animal was intubated with a $3.5 \mathrm{~mm}$ endotracheal tube without cuff and held in isoflurane.

The third eyelid was pulled gently to cover the entire cornea and three anchorage points (dorsal, lateral and ventral) in relation to the temporal canthus were performed. A section of an intravenous tubing (capton) helped to distribute the suture pressure over a wider area of the eyelids. Initially, a 6-0 nonabsorbable polypropylene (Prolene ${ }^{\circledR}$, Ethicon, São Paulo, Brazil) suture was placed through a capton and then through the upper eyelid about $0.5 \mathrm{~cm}$ caudal to the lid margin. The suture exited the eyelid in the dorsal conjunctival fornix. Then the suture was passed completely through the third eyelid two times very close to the edge. After that the suture was directed back into the dorsal conjunctival fornix, out the upper eyelid, and through the capton. This procedure was repeated about $0.5 \mathrm{~cm}$ away from the temporal canthus and in the lower eyelid as illustrated in Figure 1B. Finally all of the three

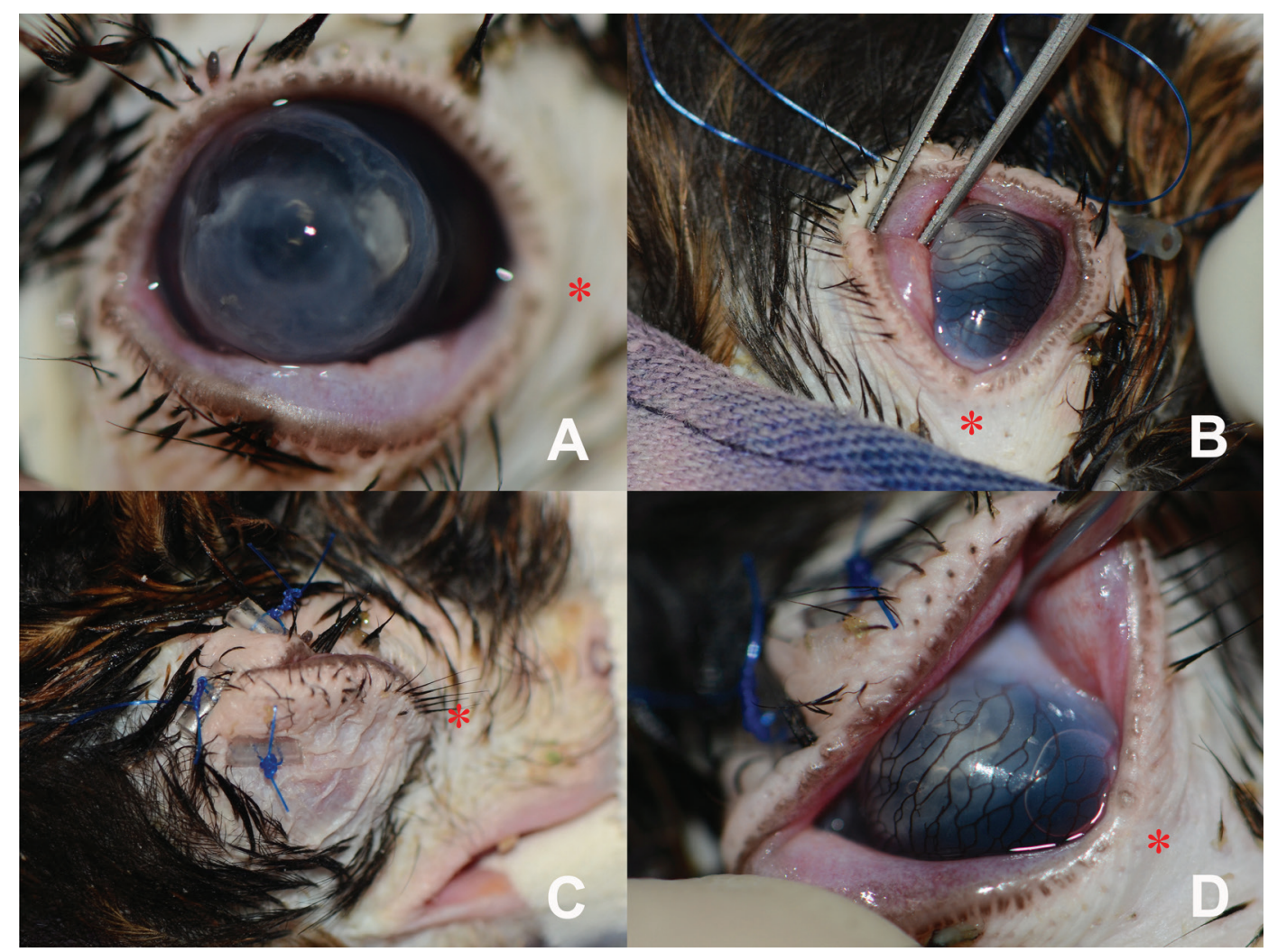

Fig.1. (A) Bullous keratopathy in a yellow-headed caracara (Milvago chimachima). Note a blurred bullous lesion, with irregular surface, occupying almost the entire cornea. (B,C) Modified third eyelid flap fixed at three anchorage points in the temporal canthus. (B) Passage of surgical sutures, (C) final aspect of the eyelids and (D) the nictitating membrane. 


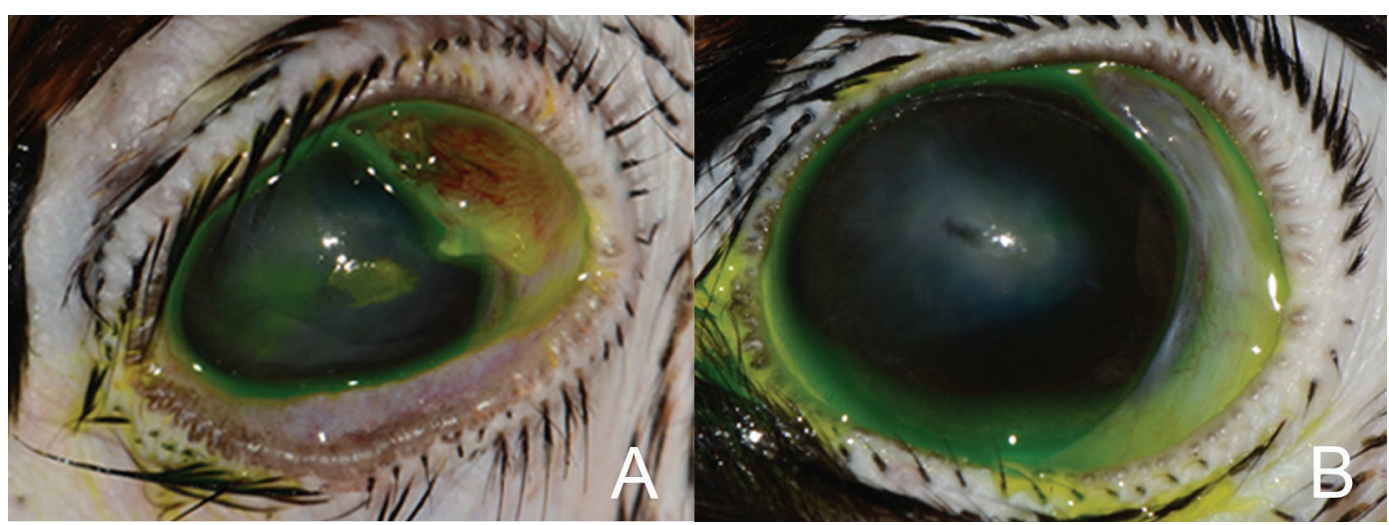

Fig.2. (A) Post-operative follow up of a bullous keratopathy in a yellow-headed caracara (Milvago chimachima). Note edema and hyperemia in the third eyelid and a central superficial ulcerative corneal lesion 21 days after removal of the modified third eyelid flap. (B) Appearance of the eye after the end of treatment (29 days) with a negative fluorescein staining and a corneal scar (macula).

sutures were tighten and pulled the third eyelid over the cornea but not enough to constrict the eyelids (Fig.1C,D)

A single injection of enrofloxacin (Flotril ${ }^{\circledR}$, Schering-Plough, São Paulo, Brazil), (7.5mg kg-1 i.m) was admistered immediately after surgery. A 3-day course of systemic flunixin meglumine (Banamine ${ }^{\circledR}$, Schering-Plough, São Paulo, Brazil, 1mg kg-1, i.m, once a day) was performed. In addiction topic ciprofloxacin (Ciloxan ${ }^{\circledR}$, Alcon, São Paulo, Brazil) and hyaluronic acid eyedrops (Ocucan ${ }^{\circledR}$, Disop, Madrid, Spain), every 12 hours until sutures removal were dispensed.

The progression of corneal healing and diminished of the blurred aspect was possible to follow during handling to medicate the animal, because of the thin and transparent third eyelid. Twenty one days after surgery, due to the reduction of corneal volume, the third eyelid flap was removed. Therefore, the animal was physically restrained and each capton was removed after cutting and traction of the surgical thread. It is worth mentioning that after removal of the sutures the third eyelid remained adhered to the temporal canthus. The dissection of the conjunctiva was performed, with a Westcott scissors after instillation of proximetacaine hydrochloride eye drops (Anestalcon ${ }^{\circledR}$, Alcon, São Paulo, Brazil).

At ophthalmic inspection moderate inflammatory reaction of the third eyelid was identified (Fig.2A) without compromising their mobility. The animal was comfortable and the cornea, less prominent and edematous but still with the presence of a small superficial stromal lesion (Fig.2A). An 8-day course of ciprofloxacin (Ciloxan ${ }^{\circledR}$, Alcon, São Paulo, Brazil) and hyaluronic acid $\left(\right.$ Ocucan $^{\circledR}$, Disop, Madrid, Spain) eyedrops, every 12 hours, were maintained and after that a negative fluorescein staining and a corneal scar (macula) was observed (Fig.2B). The third eyelid did not show any signs of abnormalities (Fig.2B). However, this opacity did not prevent the bird to see.

\section{DISCUSSION AND CONCLUSION}

The bullous keratopathy (BK) although described in dogs and cats has an unusual presentation in other animals (Ortiz et al. 2011, Jégou \& Tromeur 2015). In birds there is only one BK report in a Great Horned Owl (Bubo virginianus) associated with trauma, which was treated initially with a temporary tarsorrhaphy and the use of topical antibiotics and hyperosmotic. However, no success was achieved and a penetrating keratoplasty with an overlying pedicle graft was performed, which allowed after a few months the resolution of the ophthalmic lesion (Gionfriddo \& Powell 2006).
A common sign presented by humans and domestic animals with BK is the intense eye discomfort demonstrated through blepharospasm, increased eyelid incursions or behavioral change that was not observed in this case (Pires et al. 1999, Ortiz et al. 2011).

In more advanced stages, in which the BK occupies a large portion of the cornea, the use of topical medications such as steroids, $5 \%$ sodium chloride, antiglaucoma drugs, are not effective for clinical resolution as observed by Gionfriddo \& Powell (2006). In humans it has been investigated the use of collagen cross-linking for the treatment of BK and good results have been obtained depending on the severity of the lesion (Arora et al. 2013). However, recent studies in dogs and cats suggests that new studies should be conducted to validate this technique (Pot et al. 2015, Spiess et al. 2014).

More complex and effective surgical procedures such as aminiotic membrane transplantation (Pires et al. 1999), superficial keratectomy (Jégou \& Tromeur 2015), deep lamellar endothelial keratoplasty or penetrating keratoplasty (Gionfriddo \& Powell 2006, Zhao et al. 2013) could be employed in the presented case but these techniques require special equipment that restrict their use to large centers (Martin 2005). Thus, we opted for a modified third eyelid flap, which is a technique of simple execution and is widely used for treatment of BK in cats (Martin 2005). It is worth mentioning that despite being contraindicated in birds, this technique enabled the restoration of corneal arrangement with visual preservation of the Yellow-headed Caracara without compromising the anatomy and physiology of the third eyelid.

\section{REFERENCES}

Arora R., Manudhane A., Saran R.K., Goyal J., Goyal G. \& Gupta D. 2013. Role of corneal collagen cross-linking in pseudophakic bullous keratopathy: a clinicopathological study. Ophthalmology 120:2413-2418.

Famose F. 2014. Assessment of the use of spectral domain optical coherence tomography (SD-OCT) for evaluation of the healthy and pathological cornea in dogs and cats. Vet. Ophthalmol. 17:12-22.

Gionfriddo J.R. \& Powell C.C. 2006. Primary closure of the corneas of two Great Horned owls after resection of nonhealing ulcers. Vet. Ophthalmol. 9:251-254.

Glover T.L., Nasisse M.P. \& Davidson MG. 1994. Acute bullous keratopathy in the cat. Vet. Comp. Ophthalmol. 4:66-70. 
Harris M.C., Schorling J.J., Herring I.P., Elvinger F., Bright P.R. \& Picket J.P. 2008. Ophthalmic examination findings in a colony of screech owls $(\mathrm{Me}$ gascops asio). Vet. Ophthalmol. 11:186-192.

Jégou J.P. \& Tromeur F. 2015. Superficial keratectomy for chronic corneal ulcers refractory to medical treatment in 36 cats. Vet. Ophthalmol. 18:335-340.

Maggs D.J., Miller P.E. \& Ofri R. 2013. Slatter's fundamentals of veterinary ophthalmology. 5th ed. W.B. Saunders, Missouri. 506p.

Martin C.L. 2005. Cornea and sclera in ophthalmic disease in veterinary medicine, p.273. In: Ibid. C.L. (Ed.), Ophthalmic Disease in Veterinary Medicine. Manson Publishing, London.

Ortiz J.P.D., Lisbão C.B.S., Brito F.L.C., Martins B. \& Laus J.L. 2011. Superficial keratectomy and $360^{\circ}$ conjunctival flap for bullous keratopathy in a dog: a case report. Arq. Bras. Med. Vet. Zootec. 63:773-777.

Ossa V.J. \& Ossa-Lacayo A. 2011. Aspectos de la densidad poblacional e historia natural de Milvago chimachima (Aves: Falconidae) em el área urbana de sincelejo (Sucre, Colombia). Univ. Sci., Bogotá, 16:63-69.

Pires R.F., Tseng S.G., Prabhasawat P., Puangsricharern V., Maskin S.L., Kim J.C. \& Tan D.T.H. 1999. Amniotic membrane transplantation for symptomatic bullous keratopathy. Arch. Ophthalmol. 117:1291-1297.

Pot S.A., Gallhofer N.S., Walser-Reinhardt L., Hafezi F. \& Spiess B.M. 2015. Treatment of bullous keratopathy with corneal collagen cross-linking in two dogs. Vet. Ophthalmol. 18:168-173.

Spiess B.M., Pot S.A., Florin M. \& Hafezi F. 2014. Corneal collagen cross-linking (CXL) for the treatment of melting keratitis in cats and dogs: a pilot study. Vet. Ophthalmol. 17:1-11.

Willis A.M. \& Wilkie D.A. 1999. Avian ophthalmology. I. Anatomy, physical examination and diagnostic techniques. J. Avian Med. Surg. 13:160-166.

Zhao H., Luo Y., Niu C. \& Guan W. 2013. Comparison of treatments for bullous keratopathy in rabbits. Exp. Ther. Med. 5:1481-1485. 